\title{
Covid-19 pandemic has derailed progress on sustainable development goals, says WHO
}

\author{
Jacqui Thornton
}

London

The rate of progress towards the United Nations' sustainable development goals is too slow and is being further "thrown off track" by the covid-19 pandemic, the World Health Organization has said.

The warning came from Tedros Adhanom Ghebreyesus, WHO director general, as the agency published the 2020 edition of its annual World Health Statistics, ${ }^{1}$ reporting progress against a series of key health and service indicators.

In 2015 the United Nations adopted the 2030 Agenda for Sustainable Development, which includes 17 goals with 169 targets. ${ }^{2}$ With only a decade to the deadline, the latest report shows that life expectancy and healthy life expectancy have increased, but unequally.

The biggest gains were reported in low income countries, which saw life expectancy rise by $21 \%$ ( 11 years) between 2000 and 2016 , compared with an increase of $4 \%$ (3 years) in higher income countries.

One driver of progress was improved access to services to prevent and treat HIV, malaria, and tuberculosis, as well as some neglected tropical diseases such as guinea worm. Another was better maternal and child healthcare, which led to a halving of child mortality from 2000 to 2018 .

But in other areas progress has been stalling. Immunisation coverage has barely increased in recent years, and there are fears that malaria gains may be reversed.

In 2017 only a third to a half of the world's population had access to essential health services. Over $40 \%$ of all countries have fewer than 10 medical doctors per 10000 people. And over $55 \%$ of countries have fewer than 40 nursing and midwifery personnel per 10000 people.

Over half $(55 \%)$ of the global population was estimated to lack access to safely managed sanitation services, and over a quarter (29\%) lacked safely managed drinking water. Particularly worryingly given the current pandemic, two in five households worldwide $(40 \%)$ lacked basic handwashing facilities with soap and water in their home.

\section{Urgent need to invest}

Ghebreyesus said, "The good news is that people around the world are living longer and healthier lives. The bad news is the rate of progress is too slow to meet the sustainable development goals and will be further thrown off track by covid-19.

"The pandemic highlights the urgent need for all countries to invest in strong health systems and primary healthcare as the best defence against outbreaks like covid-19 and against the many other health threats that people around the world face every day. Health systems and health security are two sides of the same coin."

The World Health Statistics report detailed an overall shortage of services, in and outside the health system, to prevent and treat non-communicable diseases (NCDs). In 2016, $70 \%$ of all deaths worldwide were attributable to NCDs, and most (85\%) occurred in low and middle income countries.

Katie Dain, chief executive of the NCD Alliance, said, "This report reinforces what the current covid-19 pandemic has already taught us-that a failure to invest in health is a failure to invest in a country's own security."

The report also highlighted the need for stronger data and health information systems, owing to "uneven capacities to collect and use accurate, timely, and comparable health statistics."

This presents a major challenge in enabling countries to prepare for, prevent, and respond to health emergencies such as the ongoing covid-19 pandemic. WHO is supporting countries in strengthening surveillance and data and health information systems so that it can measure their status and manage improvements.

Samira Asma, WHO assistant director general, said, "As the world battles the most serious pandemic in 100 years, just a decade away from the SDG [sustainable development goal] deadline, we must act together to strengthen primary healthcare and focus on the most vulnerable among us in order to eliminate the gross inequalities that dictate who lives a long, healthy life and who doesn't."

1 World Health Organization. World health statistics 2020. May 2020. https://www.who.int/ gho/publications/world health statistics/en/.

Gulland A. UN adopts new global health targets to supersede the millennium goals. BM 2015;351:h5177. 10.1136/bmj.h5177 26416224

Published by the BMJ Publishing Group Limited. For permission to use (where not already granted under a licence) please go to http://group.bmj.com/group/rights-licensing/ permissions 